\title{
Stitching the Loop with Electronic Textiles
}

\author{
Promoting Equity in High School Students' Competencies and Perceptions of Computer Science \\ Yasmin B. Kafai ${ }^{\top}$ \\ kafai@upenn.edu \\ Mia S. Shaw ${ }^{\top}$ \\ mshaw12@gse.upenn.edu \\ Deborah A. Fields* \\ deborah.fields@usu.edu \\ Gayithri Jayathirtha
gayithri@gse.upenn.edu \\ Debora A. Lui ${ }^{\top}$ \\ deblui@upenn.edu \\ Tomoko M. Nakajima
tnak@493@g.ucla.edu \\ Justice T. Walker ${ }^{\top}$ \\ justicew@gse.upenn.edu \\ Joanna Goode $\neq$ \\ goodej@uoregon.edu \\ Michael T. Giang^ \\ mtgiang@cpp.edu \\ ${ }^{\top}$ Graduate School of Education, University of Pennsylvania, Philadelphia, PA, U.S.A. \\ *Instructional Technologies and Learning Sciences, Utah State University, Logan, UT U.S.A. \\ ${ }^{\circ}$ Urban Schooling, University of California, Los Angeles, Los Angeles, CA U.S.A. \\ \#Education Studies, University of Oregon, Eugene, OR, U.S.A. \\ ^Psychology and Sociology, Cal Poly Pomona, Pomona, CA U.S.A.
}

\begin{abstract}
Many efforts of curricula design have concentrated on expanding participation in K-12 CS education by introducing innovative approaches but few have focused on addressing longstanding equity issues through their choices of culturally relevant materials and activities. In this paper, we describe our efforts in using electronic textiles which include Arduino-based microcontrollers that are sewn with conductive thread on fabrics to connect actuators and sensors and create interactive wearables. We report on the implementation of an electronic textiles curricular unit in the Exploring Computer Science introductory computing course in 13 high schools involving 272 high school students largely from underrepresented groups in a major metropolitan school district. We examined two issues relevant to broadening equitable participation in CS: (1) students' changed perceptions of computing, and (2) students' depth of learning of computing, circuitry and crafting in the final project. Pre/post surveys on students' perceptions of computing showed positive, significant gains in students' self-confidence in solving CS problems, fascination with computing and ability to be creative with computing. Teacher evaluations of students' final projects revealed robust learning in the areas of basic programming and computational circuitry as well as strong learning across more challenging computational concepts, with room for growth. We discuss factors that impacted student outcomes and outline steps for further analysis.
\end{abstract}

Permission to make digital or hard copies of all or part of this work for personal or classroom use is granted without fee provided that copies are not made or distributed for profit or commercial advantage and that copies bear this notice and the full citation on the first page. Copyrights for components of this work owned by others than ACM must be honored. Abstracting with credit is permitted. To copy otherwise, or republish, to post on servers or to redistribute to lists, requires prior specific permission and/or a fee. Request permissions from Permissions@acm.org.

SIGCSE '19, February 27-March 2, 2019, Minneapolis, MN, USA

(C) 2019 Association for Computing Machinery.

ACM ISBN 978-1-4503-5890-3/19/02...\$15.00

https://doi.org/10.1145/3287324.3287426

\section{CCS CONCEPTS}

- Social and professional topics $\rightarrow$ Computer science education; Computational thinking $\bullet \mathrm{K}-12$ Education

\section{KEYWORDS}

high school computer science, electronic textiles, equity, computer science education, curriculum, Exploring Computer Science, computer science attitudes

\section{ACM Reference format:}

Yasmin B. Kafai, Deborah A. Fields, Debora A. Lui, Justice T. Walker, Mia S. Shaw, Gayithri Jayathirtha, Tomoko M. Nakajima, Joanna Goode, and Michael T. Giang. 2019. Stitching the Loop: Results from an Electronic Textiles Curriculum on High School Students' Competencies and Perspectives of Computer Science. In Proceedings of $50^{\text {th }}$ ACM Technical Symposium on Computer Science Education (SIGCSE '19), February 27-Mar. 2, 2019, Minneapolis, MN, USA. ACM, New York, NY, USA, 7 pages. https://doi.org/10.1145/3287324.3287426

\section{Introduction}

Current national initiatives to expand computer science to all through K-12 education face many formidable challenges in addressing the lack of access to computers, courses, and teachers [23] as well as missing teacher preparation and certification [7]. Efforts have also concentrated on developing curricula for K-12 education that contextualize introductory CS concepts and practices by using application design or integrating CS into other disciplinary content (e.g., science [35], mathematics [32]); however, few efforts have focused on promoting culturallyrelevant contexts and activities [14] that address the needs of underrepresented groups.

Most well-known efforts in culturally-relevant computing design and tools (e.g., [8]) leverage connections between existing cultural practices and concepts of computing. More recent 
developments have focused on bringing in materials and practices that promote the design of new computing artifacts. One example includes electronic textiles (hereafter: e-textiles) that connect sewable microcontrollers with conductive thread to actuators such as LEDs as well as sound, light or touch sensors to make interactive craft projects [3]. Such projects are far more popular with female designers than traditional Arduino projects whose designers tend to be predominantly male and focus on robot and drone designs [4]. Research on e-textiles in K-12 education has shown their potential to introduce basic circuitry [29] and computing to high school students [19]. However, studies in which students design multiple and more advanced etextile projects and in which classroom teachers (rather than researchers) lead the intervention are still rare and the focus of this paper.

In this paper, we describe the implementation of our etextile high school curriculum unit and how this influenced student perceptions and learning competencies. Our unit is situated within the larger context of Exploring Computer Science [12], an introductory year-long computer science curriculum. Three equity issues-broadening access, diversifying representation (by privileging non-dominant CS learners, techniques, and artifacts), and deepening participation-formed the impetus for developing the e-textiles curriculum [9]. We report on the content of the curriculum unit and its implementation in 15 classrooms (in 13 schools) with 272 high school students from largely underserved communities in a major metropolitan school district to address the following research questions: (1) To what degree was there equity in changing perceptions of CS across students? and (2) To what degree did all students demonstrate depth of competence in computing, circuitry and crafting, in finishing the final, and most challenging project of the unit? To evaluate these questions, we used pre/post surveys on students' perceptions of CS and teacher evaluations of students' final projects. In the discussion, we address opportunities and challenges of implementing equitable CS activities.

\section{Background}

The focus on curriculum reform in CS education began in the early 2000s with NSF's support in the development, piloting, and scaling of year-long introductory and advanced computer science courses, resulting in Exploring Computer Science and $A P$ Computer Science Principles [6]. These courses were explicitly designed with the belief that a more engaging and culturally responsive curriculum would attract and retain students from historically underrepresented groups. In addition to these wellestablished foundational courses, there has been a rhizomatic spread of curricular efforts that have showcased innovative and novel approaches to teaching high school students about particular topics or approaches to computing. These include (1) courses with a foundational breadth approach to teaching computer science (e.g., CS Discoveries by code.org), (2) courses which focus on particular application design such as games [30], and (3) courses which are situated within disciplinary STEM contexts such as Bootstrap for algebra [32] or StarLogo for complex systems in science [35].

There have been far fewer efforts in course development which situate key computational concepts and practices in culturally-relevant contexts [8]. For instance, Exploring Computer Science (hereafter: ECS) was specifically developed to challenge the persisting underrepresentation of women and people of Color in computing, as well as the systemic and political barriers that continue to exist in computer science education [14]. In ECS, students learn through inquiry and project-based activities, and develop a repertoire of computational practices [12] which connect computing with students' everyday experiences [33]. Over the last 10 years, ECS has prepared over 3000 teachers through a comprehensive two-year professional development program. Each year, approximately 50,000 diverse high school students enroll in ECS courses across the nation.

We chose to situate our e-textile unit within ECS because the design of its curriculum activities and teaching already addresses aspects considered critical for equity-minded and inquiry-oriented programming instruction [27] such as (1) time because students are introduced to a variety of CS concepts and practices within the context of a year-long curriculum, (2) diversity because students engage with a range of different CS contexts such as data science, robotics, programming and HCI, and (3) reflection because students review and describe their learning throughout the curriculum. Previous evaluations have consistently demonstrated that ECS is successful in significantly increasing students' perceptions of CS [13, 24].

In this larger scale implementation across many classrooms, we wanted to examine whether these initial successes of broadening students' perspectives and deepening their learning about CS would extend to the new e-textile unit. We wondered if the introduction of personalized handcrafts in conjunction with electronics in academic CS classes within schools that serve marginalized populations, would help broaden students' interest and perspectives about CS. Handcrafts practices are more inclusive of gendered [28] and indigenous [25] influences, can help students strengthen connections to history and cultures, and can be linked to content knowledge in school. Although such work has been long considered vocational, non-academic, and low-tech [31] in contrast to most CS activities that require programming, engineering skills, and high-tech tools, their inclusion diversifies materials and practices to promote interest and broaden application. Furthermore, designing open-ended projects with e-textiles is unlike the more constrained design of robotics or games in other ECS units and allows students to personalize their designs.

In terms of deepening student learning about CS, we entered new territory. Most previous e-textile activities in K-12 education focused on students' learning simple circuits or relatively basic lighting sequences rather than engaging more extensively with computing [15]. In designing our curriculum, we included a series of increasingly difficult e-textile projects that introduced challenging concepts in coding, circuitry, and crafting [9]. Furthermore, prior e-textiles activities in afterschool, museum, and even classroom settings were almost all 
facilitated by researchers (e.g., [2, 18, 21]), whereas existing CS classroom teachers led our program implementation with their own students. We know from pilot implementations of the etextile unit within two ECS classrooms that teachers used equitable practices such as modeling mistakes, legitimizing student expertise, and promoting connected learning in their public-school classrooms with up to 35 students $[9,10,11]$. In this study we expanded our pilot implementation to 15 classrooms and examined to what degree the e-textiles unit was able to reach all students in breadth of interest and depth of learning.

\section{Methods}

\subsection{Curriculum Content}

ECS and e-textile experts co-developed the curricular unit to be taught as one of the final units of the ECS course, replacing either the Data or Robotics units. The resulting e-textile activities follows the ECS model, containing big ideas and recommended lesson plans, with much room for teachers to interpret and bring in their own approaches. In the design of the four e-textiles projects, we prioritized helping students learn challenging concepts in computing, electronics, and crafting while also supporting personal expression and design (for design principles of the unit, see [17]; for descriptions of all projects, see [9, 10]). The fourth and final project incorporates a handmade human sensor created from two aluminum foil conductive patches that when squeezed generate a range of data (see Figure 1, Project \#4). Students must determine the range of data useful for their project (how hard they want people to squeeze) and break that into a set of at least four conditions that trigger different lighting patterns (e.g., no squeezing, light squeezing, hard squeezing, etc.).

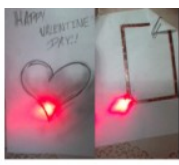

Project 1:

E-Cards

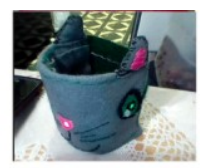

Project 2:

Wristbands

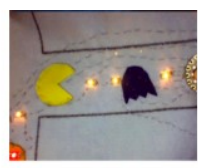

Project 3:

Class Banner

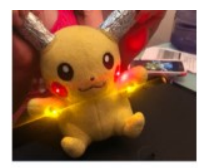

Project 4: Human Sensor

Figure 1: Samples of the four types of e-textile projects.

While introducing new circuitry and crafting skills, the etextiles unit builds on students' prior programming skills developed through the ECS Scratch unit. Drawing upon student understanding of computational concepts such as sequences, loops, conditionals, and variables, it requires students to apply these in a new context: a text-based programming language (Arduino). In addition, students learn new programming skills such as nested conditionals, data input from sensors, and functions. Learning these challenging skills in the context of making handcrafted, personalized objects helped support our goal of diversifying the computational artifacts used in CS classes.

\subsection{Participants}

In Spring 2017, the ECS-school district liaison in a large metropolitan area in California sent an invitation to the ECSteacher listserv for educators to participate in the third and final year of the e-textiles pilot study. Teachers and school sites were chosen by the liaison for their diverse teaching styles, to maximize the variety of feedback on the curriculum. The liaison included himself as a pilot teacher. Lastly, when two teachers announced their need to take maternity leave mid-pilot, the replacement teachers were identified through snowball sampling. The final number of educators was 15 with teaching experience ranging from 3 and 37 years; most but not all also had taught ECS for several years. All teachers engaged in four days of e-textile professional development over a period of four months, where they became familiar with the curriculum by creating the projects from the unit and reflecting on the pedagogy used during professional development.

In Spring 2018, 15 teachers implemented the e-textile unit in their ECS classes; classes ranged from 20-42 students. The unit lasted between 8 and 13 weeks, depending on the classroom. There was a wide variety in approaches and modifications among implementing teachers. Over 430 students participated but only 359 provided consent to collect their data for research purposes. Of these 272 completed both pre- and post-surveys. For participating schools, percentages of students from ethnically underrepresented groups (i.e., non-white) ranged between $72 \%$ and $99 \%$; English as a second language between $2 \%$ and $41 \%$; and those with reduced lunch between $47 \%$ and $97 \%$.

\subsection{Data Collection}

To investigate student perceptions and learning, we focused on two sources of data: (1) students' perceptions of CS and their own competence using a pre-post survey, and (2) teachers' evaluations of student competence (via a grading rubric assessment of students' final e-textile project \#4, with human sensors).

3.3.1 Student Pre-Post Surveys. Students were given a CS in E-Textiles Survey before (pre-survey) and immediately after (post-survey) participating with the ECS electronic textiles unit. At the demographic level, students answered questions about gender, ethnic identification, prior experience with CS courses, language spoken at home, and family college attainment. In terms of their perceptions about CS, five categories were assessed using a 4-point Likert scale (ranged from strongly disagree (1) to strongly agree (4): (1) self-confidence in solving CS-based problems (5 items; e.g., "I think I am very good at explaining my solutions to technical problems"), (2) fascination with CS (4 items; e.g., "Designing new things makes me feel excited"), (3) value of CS in future endeavors (2 items; e.g., "knowing computer science is important for contributing to my community"), (4) the ability to express personally through CS activities (3 items; e.g., I can be creative in computer science"), and (5) the ability to carry out electronic textile-based activities (post-survey only, 9 items; e.g., "identify a problem in someone else's circuit diagram for an e-textile project"). The self- 
confidence, fascination, and value of CS items were based on an instrument previously published by the Activation Lab [1, 26] which measures the affective and cognitive aspects of student interests toward science topics or tasks. The survey items were adjusted from reflecting on science to computer science while items focused on personal expression with CS were newly created.

3.3.2 Grading Rubric. As part of the curriculum, teachers were provided a grading rubric to evaluate students' performance on the final project of the unit using human sensors. This rubric was organized as follows:

- Coding (30 points) for having the general structure of code including variable declaration, input/output setup and the appropriate conditionals (15 points), four complete lighting pattern functions ( 5 points), appropriately commented code (5 points), and functional sensors (5 points).

- Circuity (20 points) for the completion and clarity of the circuit design (15 points), and functionality of the LED circuits themselves (5 points).

- Design \& Craft (50 points) for fulfilling the basic requirements of having four independently controllable lights and two sensor patches (10 points), aesthetics and finishing (15 points), sewing (15 points), and design notebook completion (10 points).

Following the unit, teachers were asked to evaluate their students' projects based on this rubric and submit these to the researchers.

\subsection{Data Analysis}

Student Demographics. In all analyses, we used the following demographic information provided by students. Gender was defined across three categories including: male, female and decline to indicate. Race/ethnic identification was defined across seven categories including: Hispanic/Latinx, AfricanAmerican/Black, Asian-American, White/Caucasian, Other, Biracial and decline to indicate. Primary home language was a measure of the extent to which students spoke a language other than English at home (responding "never, once in a while, most of the time, and all of the time."). Family college attendance was defined as whether or not a student had an immediate or extended family member who had attended college.

3.4.1 Student Pre-Post Surveys. We evaluated the entire sample of students who completed both a pre- and post-survey for all constructs except for those related to e-textile activities. We first validated each of the five survey constructs empirically by calculating Cronbach alpha reliability scores using survey items in each construct. Scores with $a>0.800$ reflect good consistency among items in a given construct. Scores with a> 0.700 reflect fair consistency. The self-confidence construct had a pre and post Cronbach alpha score of $\mathrm{a}=0.747$ and $\mathrm{a}=0.848$, respectively; fascination pre and post scores were $\mathrm{a}=0.767$ and $a=0.800$; CS value pre and post scores were $a=0.721$ and $a=0.770$; personal expression pre and post scores were $\mathrm{a}=0.893$ and $\mathrm{a}=0.860$; e-textiles skills (post-survey only) score was $\mathrm{a}=0.890$. Thus, all constructs passed the threshold for survey validation.

To provide insights into overall differences in student perspectives before and after participating in the e-textiles curricular unit, paired sample t-tests were conducted for (1) confidence, (2) fascination, (3) value and (4) expression. Analyses of variance (ANOVAs) were conducted to assess differences that may exist across the self-reported social and economic demographic categories (gender, race/ethnicity, home language, and family college attendance). These ANOVAs were conducted with the post-survey composite in order to ascertain differences in student perspectives after having participated in the e-textiles curricular unit.

3.4.2 Grading Rubric. As a measure of learning, we compiled rubric scores from teachers and calculated descriptive statistics mean, range, and median) across individual students' total scores, composite theme scores (Coding, Circuitry, Design \& Crafting), and subtopic scores, (e.g., sensor functionality, circuit diagram) to compare student accomplishments in these different areas. Because students were scored using four fixed levels across each subtopic, we also performed a count and percentage of student scores (e.g., for a range of 10 , a score of $0,3,6$, or 10) and compared these across the other subtopics as another point of comparison.

For this grading rubric analysis, only 8 of 15 classrooms are included for a total of $\mathrm{N}=174$ students. The other classes were not included because either they did not finish all four projects and therefore did not submit human sensor rubric scores $(\mathrm{N}=5)$, or they did complete the human sensor projects but provided incomplete rubric scores for the project, specifically, the total score out of 100 rather than the individual theme and subtopic scores (e.g., Circuitry, Sensor Functionality) $(\mathrm{N}=2)$.

\section{Findings}

\subsection{Student Perceptions of CS}

Across student perceptions of CS, we found significant increases in three of the four constructs after participating in the e-textile curriculum (see Table 1). The self-confidence outcome suggests that overall, students perceived themselves as more confident in solving CS-related technical problems or challenges after participating in the e-textiles activity. The fascination outcome suggests that students reported being more interested in learning about computer science after having participated in the e-textiles activity. The CS expression outcome suggests that students felt that they could engage with activities that are of personal interest in computer science. However, there was no change $(p>0.05)$ in student responses about their perceived CS value of computer science for future endeavors.

\begin{tabular}{llll}
\hline Variable & $\begin{array}{l}\text { Pre-Survey } \\
\text { Mean (SD) }\end{array}$ & $\begin{array}{l}\text { Post-Survey } \\
\text { Mean }(S D)\end{array}$ & $\begin{array}{l}\text { Demographic } \\
\text { Differences }\end{array}$ \\
\hline Confidence & $15.04(2.2)$ & $15.54(2.397)^{*}$ & None \\
Fascination & $12.58(2.334)$ & $12.89(2.307)^{*}$ & None \\
Expression & $9.6(2.00)$ & $10.03(1.808)^{*}$ & None \\
Value & $6.33(1.314)$ & $6.27(1.364)^{*}$ & Gender ${ }^{* *}$ \\
\hline Note ${ }^{*} \mathrm{p}<0.05,{ }^{* *} \mathrm{p}<0.001$ & & \\
\hline
\end{tabular}

Table 1: Differences between pre- and post-surveys $(\mathrm{N}=272)$. 
Demographic comparisons did not yield any significant differences in how students responded to post-survey questions related to confidence in $\mathrm{CS}$, fascination with $\mathrm{CS}$, and overall etextiles skills and capabilities (ANOVA), suggesting that the etextiles unit was relevant to students' interest, confidence, and sense of creativity with CS regardless of gender, ethnicity, language and family education. Furthermore, while there were no overall pre- and post-survey differences on constructs related to student CS value, an ANOVA revealed that male students reported valuing computer science for future academic and professional studies more than female students after working with e-textiles. These findings suggest that in some categories traditional inequities can persist and require further work.

Regarding e-textile abilities, mean scores show that students felt "very confident" or "confident" in all areas, with some minor differences. Overall students showed high confidence (mean scores between 3.10-3.59) in areas of crafting, circuitry, and basic coding sequences. Students were slightly less confident (mean scores between 2.97-3.00) in areas of diagnosing coding problems with sensors (which require Boolean logic and conditionals) and troubleshooting another person's code. There were no differences regarding the four demographic areas in an ANOVA. As we will show, these self-assessed areas of confidence matched well with the areas of teacher-rated competence in the final project.

\subsection{Student CS Competence}

One of the goals for the e-textiles unit was that students create personally relevant e-textile artifacts through open-ended projects with creative constraints to support depth of learning [17]. This goal was met in all 15 classrooms. Preliminary examination of student artifacts illustrated diversity of project designs despite having the same requirements and materials provided in the curriculum. Whereas some students 'hacked' existing fabric artifacts such as their own t-shirts, hats, and stuffed animals by adding LEDs and sensors, still others created original soft projects (both flat and 3-D) such as banners or pillows using felt and glue (see Figure 1). Students drew from diverse sources for inspiration including popular culture (e.g., Spiderman, Finding Nemo, M\&M candies), personal interests and affiliations (e.g., an outer space scene, a school logo t-shirt), and/or their own names (i.e., nicknames, initials). The findings that students could be creative in the unit was reflected in their survey answers, particularly in the category of personal expression.

4.2.1 Teacher Evaluation of Coding and Circuitry. Turning to teachers' evaluations of the final human sensor project from eight classrooms, students' total scores ranged from 16 to 100 (out of a possible 100 points), with a mean of 79.4, and a median of 83. Overall students performed well on the final projects. We further considered the spread of scores in different areas of the rubric. Students scored the highest in the overall themes of Design \& Crafting (average of $87.5 \%$ out of 50 pts), and Circuitry (average of $87 \%$ out of 20 pts), and lowest in Coding (average of $61 \%$ out of $30 \mathrm{pts})$. We investigate these areas more deeply below.
The overall Circuitry score was calculated from two underlying subtopics: a workable circuitry blueprint and actual working LED circuits (see section 3.3.2). Overall, students scored relatively well on both. Regarding clear and workable circuitry blueprints, $93.1 \%$ of students received the top two scores, with $76.4 \%$ of students receiving the highest possible score. Regarding functional LED circuits that turned on, $87.4 \%$ of students scored in the top two scores with $70.7 \%$ of students receiving the highest score. Scoring in the top two categories demonstrates strong performance in these areas with either perfect work (highest score) or close to perfect work (second highest score). From this vantage point, nearly all students generally gained a strong understanding of circuit fundamentals in the class, including knowledge of polarity, short circuits, and spatial design of programmable circuits.

The overall Coding score was calculated from four underlying categories (see section 3.3.2): having four lighting patterns, clearly structured program code, commented code, and functional sensors. Compared to other categories, students generally received the highest scores for having four distinct lighting patterns as custom functions for controlling the LEDs (82.8\% for the top two scores, including $68.4 \%$ for the highest score). This trend makes sense considering that sequencing commands to create distinct light patterns was something students also did in project \#3, the collaborative mural project. However, students generally scored lower on both code structure-having the appropriate variable declarations, input/output setup, and conditional statements (65.5\% for the top two scores, including $51.1 \%$ with the highest score)-and functional sensors-having sensor code that read four distinct levels of pressure from working handmade sensors $(61.5 \%$ with the top two scores, $50 \%$ with the highest score). Considering that students were newly introduced to these concepts during the final human sensor project, the lower score averages in these subtopics are not surprising. Further, students worked in pairs during the collaborative mural project but independently in the final project, meaning no one could lean on a more capable partner for coding.

In the area of commented code, only $28.2 \%$ of students scored in the two upper levels (19\% with the highest score), while $69.5 \%$ of students did not comment code at all ( 0 points). While commenting is considered a fundamental skill in collaborative and large-scale software development, students perhaps felt less interested in doing so for the human sensor project since they were working alone. Similarly, they may also have prioritized completion over comments: focusing more on completing the actual code rather than leaving comments for others to decipher.

Looking across teachers' rubrics we noted that students in the classrooms where teachers had 1-2 years prior experience leading the e-textiles unit had consistently higher scores in all rubric subtopics except aesthetics and finishing, having functional LED circuits, and coding four lighting patterns (which were already high scoring areas overall). This suggests that as with other curricular implementations [24], teachers with more experience (even one year) can teach the e-textiles unit in a more 
successful way that leads to greater depth of student learning. It also fits with our knowledge of the classroom implementations, where the experienced e-textiles teachers finished the unit with time to spare whereas most inexperienced e-textiles teachers struggled to complete the unit at all (i.e., the five teachers who did not start the final human sensor project and the remaining teachers who were pressed for time at the end). We reflect more on this in the discussion.

\section{Discussion}

In this paper, we presented our efforts to implement, on a larger scale, an e-textile unit within the ECS curriculum designed to increase interest in CS and understanding of key circuit and computing concepts in high school students from predominantly underrepresented groups. Overall, our findings indicate that there was success in broadening interest in CS as reported by students themselves and to a lesser degree, in deepening the learning of computing, circuitry and crafting as evaluated by the teachers. In the following sections, we discuss these aspects in more detail in addition to considering the role of teachers.

\subsection{Broadening Student Perceptions of CS}

Our first finding is in line with outcomes from prior large-scale ECS implementations in which the course has been consistently successful in significantly increasing students' positive perceptions of CS $[14,24]$. While our e-textile unit followed the general format of ECS, it also introduced new elements such as textile materials, open-ended project designs, and a much greater emphasis on personalization of CS artifacts that provided the context for learning about computing. We know from prior research that using different materials and practices changes who participates in CS activities [4], but it was unclear whether this would extend to high school students unfamiliar with CS. Overall, our analysis revealed no gender or other demographic differences: all participants, including male high school students, indicated a broadened CS interest after working with e-textiles except in the area of future aspirations. Though many prior studies have utilized e-textiles to reach specifically to women or to underrepresented ethnic groups, our study suggests that etextiles can be an effective means to broaden interest in CS for all students. Furthermore, we examined students' perceptions of creativity with CS, an area prominently featured in AP Computer Science Principles [5], but rarely quantitatively assessed. We know from prior research with e-textiles $[2,18,17$, 34] that this is an important dimension in how students connect to CS. We hope this new survey construct allows for further comparisons of creativity and personal expression in other CS education contexts.

\subsection{Deepening Student Learning of CS}

In this study, we also tackled relatively new ground for equityoriented curricular initiatives such as ECS by assessing student learning of computing and engineering concepts from their final projects rather than a test. We observed that student performance was strong for those computing and engineering concepts that they had encountered in previous projects, while there was room for growth for those CS concepts that they encountered for the first time in the final project. These findings are not surprising given the complexities of learning to make etextiles that require students to develop an understanding of not only functional circuits but also programmable circuits [21] in the context of challenging three-dimensional crafts [20]. The rubrics allowed us to base assessment on students' actual work in an authentic manner. However, the focus on the final project limits our understanding into the processes and problem-solving students engaged in during the unit. To this end, in the future we plan to examine students' reflective portfolios which have shown promise for evaluating computational practices such as iteration, debugging, and testing [16, 22]. Such portfolios may also illuminate more about students' sense of creativity with CS.

\subsection{Designing Inclusive Curriculum Activities}

We began our investigation of implementing an e-textile unit within the ECS curriculum to understand whether new materials and practices can contribute to the overall equity agenda of broadening student perceptions of and participation in CS. While broadening perceptions is critical, we also need to make sure that students can develop a better understanding of key CS concepts and practices within the context of designing personally-relevant artifacts. Our findings suggest that providing opportunities for personal and collaborative designs are promising steps into the right direction.

Yet we recognize more needs to be done to understand teacher implementation and how to support productive classroom practices that robustly strengthen equity [11]. Thus far we already have hints that prior experience in teaching etextiles may result in stronger student learning. Looking more closely at teacher practices may yield more specific suggestions on how to support more students in going deeper with their projects. It is clear that curriculum design alone "is not enough" [14], but that professional development and pedagogy play an equally powerful role in enacting and realizing equity in classrooms. Supporting teachers across multiple years is a continuing challenge, especially in a discipline and field at large that has a long history of being exclusive of the very groups it seeks to embrace now.

Our large-scale implementation of the e-textiles unit offers one way to challenge preconceived notions of what CS can be by juxtaposing and connecting the high technologies of computing and engineering with the "low" perceived technologies of crafting and sewing. This study shows evidence that open-ended e-textiles projects can be done by teachers in regular publicschool classrooms with positive effects for students. Such introductions begin to unlock the doors to the clubhouses of computing [23].

\section{ACKNOWLEDGMENTS}

This work was supported by the National Science Foundation grant to Yasmin Kafai, Jane Margolis, and Joanna Goode (\#1509245/1512760/1510725). Any opinions, findings, and conclusions or recommendations expressed in this paper are 
those of the authors and do not necessarily reflect the views of either NSF, the University of Pennsylvania, Utah State University, University of California, Los Angeles, University of Oregon or Cal Poly Pomona.

\section{REFERENCES}

[1] Activation Lab. 2018. Retrieved on August 20, 2018 from http://activationlab.org/

[2] Beth Buchholz, Kate Shively, Kylie Peppler, and Karen Wohlwend. 2014 Hands on, hands off: Gendered access in crafting and electronics practices. Mind, Culture, and Activity, 21, 4, (July 2014) 278-297.

[3] Leah Buechley, Mike Eisenberg, Jaime Catchen, and Ali Crockett. 2008. The LilyPad Arduino: using computational textiles to investigate engagement, aesthetics, and diversity in computer science education. In Proceedings of the SIGCHI Conference on Human Factors in Computing Systems (CHI '08). ACM, New York, NY, USA, 423-432. DOI: https://doi.org/10.1145/1357054.1357123

[4] Leah Buechley and Benjamin Mako Hill. 2010. LilyPad in the wild: how hardware's long tail is supporting new engineering and design communities. In Proceedings of the 8th ACM Conference on Designing Interactive Systems (DIS '10). ACM, New York, NY, USA, 199-207. DOI $=10.1145 / 1858171.1858206$ http://doi.acm.org/10.1145/1858171.1858206

[5] College Board. 2017. Advanced Placement Computer Science Principles. Retrieved on April 20, 2018 from https://apcentral.collegeboard.org/courses/apcomputer-science-principles.

[6] Jan Cuny. 2015. Transforming K-12 computing education: an update and a call to action. ACM Inroads 6, 3 (August 2015), 54-57. DOI https://doi.org/10.1145/2809795

[7] Leigh Ann Delyser, Joanna Goode, Mark Guzdial, Yasmin Kafai, Aman Yadav. 2018. Priming the computer science teacher pump: Integrating computer science education into schools of education. CSforAll, New York, NY.

[8] Ron Eglash, Juan E. Gilbert, and Ellen Foster. 2013. Toward culturally responsive computing education. Commun. ACM 56, 7 (July 2013), 33-36. DOI https://doi.org/10.1145/2483852.2483864

[9] Deborah A. Fields, Yasmin Kafai, Tomoko Nakajima, Joanna Goode, and Jane Margolis. 2018. Putting Making into High School Computer Science Classrooms: Promoting Equity in Teaching and Learning with Electronic Textiles in Exploring Computer Science. Equity \& Excellence in Education, 51, 1 (May 2018): 21-35.

[10] Deborah A. Fields, Debora Lui, and Yasmin B. Kafai. 2017. Teaching computational thinking with electronic textiles: High school teachers' contextualizing strategies in Exploring Computer Science. In Proceedings of the International Conference on Computational Thinking Education (CTE '17), The Education University of Hong Kong, Hong Kong, China, pp. 67-72.

[11] Deborah A. Fields, Debora Lui, and Yasmin B. Kafai, Y. B. (in press). Teaching practices that support iterative design in the electronic textiles Exploring Computer Science unit. In S. C. Hong and H. Abelson (Eds.) Computational Thinking, Education. Springer.

[12] Joanna Goode, Gail Chapman, and Jane Margolis. 2012. Beyond curriculum: the exploring computer science program. ACM Inroads 3, 2 (June 2012), 47-53. DOI: https://doi.org/10.1145/2189835.2189851

[13] Joanna Goode and Jane Margolis. 2011. Exploring Computer Science: A Case Study of School Reform. Trans. Comput. Educ. 11, 2, Article 12 (July 2011), 16 pages. DOI=http://dx.doi.org/10.1145/1993069.1993076

[14] Joanna Goode, Jane Margolis, and Gail Chapman. 2014. Curriculum is not enough: the educational theory and research foundation of the exploring computer science professional development model. In Proceedings of the 45th ACM technical symposium on Computer Science Education (SIGCSE '14). ACM, New York, NY, USA, 493-498. DOI: https://doi.org/10.1145/2538862.2538948

[15] Gayithri Jayathirtha and Yasmin B. Kafai. (in press). Electronic Textiles in Computer Science Education: A Synthesis of Efforts to Broaden Participation, Increase Interest, and Deepen Learning. In Proceedings of ACM SIGCSE conference (SIGCSE '19). ACM, Minneapolis, MN USA.

[16] Gayithri Jayathirtha, Deborah A. Fields, and Yasmin B. Kafai. 2018. Computational concepts, practices, and collaboration in high school students' debugging electronic textile projects. Conference Proceedings of International Conference on Computational Thinking Education 2018, Hong Kong: The Education University of Hong Kong.
[17] Yasmin B. Kafai, and Deborah A. Fields. 2018. Some Reflections on Designing Constructionist Activities for Classrooms. In Proceedings of the Constructionism Conference 2018. Vilnius, Lithuania.

[18] Yasmin B. Kafai, Deborah A. Fields, and Kristin A. Searle. 2014. Electronic textiles as disruptive designs in schools: Supporting and challenging maker activities for learning. Harvard Educational Review, 84(4), 532-556.

[19] Yasmin B. Kafai, Eunkyoung Lee, Kristin Searle, Deborah Fields, Eliot Kaplan, and Debora Lui. 2014. A Crafts-Oriented Approach to Computing in High School: Introducing Computational Concepts, Practices, and Perspectives with Electronic Textiles. Trans. Comput. Educ. 14, 1, Article 1 (March 2014), 20 pages. DOI=http://dx.doi.org/10.1145/2576874

[20] Victor R. Lee and Deborah A. Fields. 2017. Changes in undergraduate student competencies in the areas of circuitry, crafting, and computation after a course using e-textiles. International fournal of Information and Learning Technology, 34, 5 (2017), 372-384.

[21] Breanne. K. Litts, Yasmin B. Kafai, Debora A. Lui, Justice T. Walker, and Sari A. Widman. 2017. Stitching Codeable Circuits: High School Students' Learning About Circuitry and Coding with Electronic Textiles. Fournal of Science Education and Technology, 26, 5 (May 2017), 494-507.

[22] Debora Lui, Justice T. Walker, Sherry Hanna, Yasmin B. Kafai, Deborah A Fields, \& Gayithri Jayathirtha, (in press). Communicating computational concepts and practices within high school students' portfolios of making electronic textiles. Interactive Learning Environments.

[23] Jane Margolis, Rachel Estrella, Joanna Goode, Jennifer J. Holme, \& Kimberly Nao. 2017. Stuck in the Shallow End: Education, Race and Computing, updated ed. MIT Press, Cambridge, MA.

[24] Steven McGee, Randi McGee-Tekula, Jennifer Duck, Catherine McGee, Lucia Dettori, Ronald I. Greenberg, Eric Snow, Daisy Rutstein, Dale Reed, Brenda Wilkerson, Don Yanek, Andrew M. Rasmussen, and Dennis Brylow. 2018. Equal Outcomes 4 All: A Study of Student Learning in ECS. In Proceedings of the 49th ACM Technical Symposium on Computer Science Education (SIGCSE '18). ACM, New York, NY, USA, 50-55. DOI: https://doi.org/10.1145/3159450.3159529

[25] Douglas L. Medin, and Megan Bang. 2014. Who's asking?: Native science, western science, and science education. MIT Press, Cambridge, MA

[26] Moore, D. W., Bathgate, M. E., Chung, J., \& Cannady, M. A. (2011). Technical report: Measuring activation and engagement; Activation Lab, Enables Success Study. Retrieved July 21, 2018 from http://activationlab.org/wp content/resources/aera2013/aera_research/AERA_2013_0_1_ALES2011_TechR eport.pdf

[27] David. B. Palumbo. 1990. Programming language/problem-solving research: A review of relevant issues. Review of Educational Research, 60, 1 (March 1990) 65-89.

[28] Rozsika Parker. 1984. The subversive stitch: Embroidery and the making of the feminine. Palgrave Macmillan, New York, NY.

[29] Kylie Peppler and Diane Glosson. 2013. Stitching circuits: Learning about circuitry through e-textile materials. Fournal of Science Education and Technology 22, 5 (2013), 751-763.

[30] Alexander Repenning, David Webb, and Andri Ioannidou. 2010. Scalable game design and the development of a checklist for getting computational thinking into public schools. In Proceedings of the 41st ACM technical symposium on Computer science education (SIGCSE '10). ACM, New York, NY, USA, 265-269. DOI: https://doi.org/10.1145/1734263.1734357

[31] Mike Rose. 2014. Why school? Reclaiming education for all of us. The New Press, New York, NY.

[32] Emmanuel Schanzer, Kathi Fisler, Shriram Krishnamurthi, and Matthias Felleisen. 2015. Transferring Skills at Solving Word Problems from Computing to Algebra Through Bootstrap. In Proceedings of the 46th ACM Technical Symposium on Computer Science Education (SIGCSE '15). ACM, New York, NY, USA, 616-621. DOI: https://doi.org/10.1145/2676723.2677238

[33] Kimberly A. Scott, Kimberly M. Sheridan, and Kevin Clark. 2014. Culturally responsive computing: a theory revisited. Learning, Media and Technology 40, 4 (June 2014), 412-436.

[34] Mia S. Shaw, Deborah A. Fields, and Yasmin B. Kafai, Y. B. (under review). Crafting identities: Portfolios as meta-artifacts for narrating selves in portfolios in an e-textiles class.

[35] Susan A. Yoon, Emma Anderson, Jessica Koehler-Yom, Chad Evans, Miyoung Park, Josh Sheldon, Ilana Schoenfeld, Daniel Wendel, Hal Scheintaub, and Eric Klopfer. Teaching about complex systems is no simple matter: building effective professional development for computer-supported complex systems instruction. Instructional Science 45, 1 (Feb. 2017), 99-121. 